\title{
Dose-Response Relationships Following Oral Administration of DuP 753 to Normal Humans
}

\author{
Y. Christen, B. Waeber, J. Nussberger, R.J. Lee, P.B.M.W.M. Timmermans, and H.R. Brunner
}

We assessed the inhibitory effect of DuP 753, an orally active angiotensin II receptor antagonist, on the pressor action of exogenous angiotensin I and II in healthy volunteers. In a single dose study, doses of $2.5,5,10,20$, and $40 \mathrm{mg}$ of DuP 753 or placebo were tested serially at one week intervals. In the multiple dose study, the administration of placebo or DuP $753(5,10,20$, or $40 \mathrm{mg}$, per os once daily) for eight consecutive days was evaluated. The blood pressure response to angiotensin $I$ and II was inhibited in a dose-dependent fashion with a blocking effect still present $24 \mathrm{~h}$ post drug. DuP 753 also induced a dose-dependent compensatory rise in plasma renin. This new compound was well tolerated by these normal volunteers. Thus, DuP 753 appears to be a well tolerated, orally active, potent and long-lasting antagonist of angiotensin II in humans. Am J Hypertens 1991;4:350S - 354S

KEY WORDS: Angiotensin II, DuP 753, angiotensin II antagonist.
S. aralasin ( $\operatorname{sar}^{\mathbf{1}} \mathrm{ala}^{\mathbf{8}}$-angiotensin II) was the first receptor antagonist of angiotensin (ANG) II administered to humans. ${ }^{1-3}$ This peptide antagonist was not orally active and had to be administered parenterally. Therefore, long-term antihypertensive treatment was not possible. Furthermore, the antagonist was also a partial agonist. ${ }^{4}$ Consequently, the majority of patients did not respond with a fall in blood pressure.

Furukawa and his coworkers have synthetized some imidazole derivatives that specifically block the ANG II-induced vasoconstriction. ${ }^{5}$ Important chemical modifications of these initial molecules have led to the synthesis of DuP 753.6,7 This compound is a potent antagonist of ANG II when administered orally to animals.8,9

From the Hypertension Division and Cardiovascular Research Group, University Hospital, Lausanne, Switzerland (YC, BW, JN, HRB), and E. I. du Pont de Nemours \& Company, Medical Products Dept., Wilmington, Delaware, USA, and Geneva, Switzerland (RJL, PBMWMT)

This work was supported by grants from the Cardiovascular Research Foundation, the Swiss National Science Foundation, and E. I. du Pont de Nemours \& Company.

Address correspondence and reprint requests to Hans R. Brunner, MD, Division d'Hypertension, CHUV, 1011 Lausanne, Switzerland.
We have assessed for the first time the pharmacokinetic and pharmacodynamic profile of DuP 753 after single and repeated oral administration to normal human subjects. The results suggest that DuP 753 is a potent and long-acting antagonist of ANG II not only in animals, but also in humans. ${ }^{10}$

\section{METHODS}

A total of 37 male subjects aged 20 to 38 years were recruited to carry out the two consecutive studies. All subjects were considered healthy on the basis of a medical history, a physical examination, a routine blood and urine analysis, and an electrocardiogram. The study protocols were approved by the institutional ethics committee.

In order to quantitate the pressor effect of exogenous ANG, blood pressure was measured at the finger using a photoplethysmograph (Finapres, Ohmeda, Englewood, $\mathrm{CO})$. Throughout the studies, the volunteers were allowed to continue their usual free sodium intake. They were asked to come to our research facility at $7 \mathrm{AM}$ on the first day of the investigation after fasting overnight. They were immediately placed in a supine position and venous catheters were inserted in a vein in each forearm. 
Study One (Single Dose Study) After a 30 min resting period to reach a steady baseline blood pressure and heart rate, a dose-response curve to bolus injections of ANG I was established. Angiotensin I (Senn Chemicals, Dielsdorf, Switzerland) was dissolved in $0.9 \% \mathrm{NaCl}$ to achieve a concentration of $1 \mu \mathrm{g} / \mathrm{mL}$. The bolus injections were started at a dose of $10 \mathrm{ng} / \mathrm{kg}$ and increased thereafter every 10 to $15 \mathrm{~min}$ by steps of $10 \mathrm{ng} / \mathrm{kg}$ until a systolic blood pressure increase of 25 to $40 \mathrm{~mm} \mathrm{Hg}$ was reached. This test dose was then repeated at least twice. The systolic blood pressure responses to these three consecutive injections of the test dose were averaged and the resulting mean used to define the baseline response to ANG I.

DuP 753 is the potassium salt of 2-n-butyl-4-chloro5-hydroxymethyl-1-[(2'-4H-tetrazol-5-yl)biphenyl-4yl)methyl] imidazole (E. I. du Pont de Nemours \& Company, Wilmington, DE). ${ }^{11}$ The dose to be administered was dissolved in $20 \mathrm{~mL}$ of tap water. The effect of the drug was then monitored using bolus injections of the ANG I test dose at times 15, 30, and $45 \mathrm{~min}$ and 1, 11/2, 2, $21 / 2,3,4,5,6,7,13,23,25$, and 27 (up to 33 for the $40 \mathrm{mg}$ dose) $\mathrm{h}$ after drug intake. Between the hours 7 and 12 and again between the hours 13 and 22, the subjects were allowed to leave the clinic. This two day protocol was repeated four times in each volunteer (except for one volunteer who only had 3 administrations) and at each phase a different dose of drug or placebo was given in single-blind fashion.

Study Two (Multiple Dose Study) During the multiple dose study, each subject received, in the mornings on 8 consecutive days, one dose of DuP 753 (either 5, 10, 20 , or $40 \mathrm{mg}$ ) or placebo. Thus, each dose or placebo was given in single-blind fashion to six subjects, with the exception of the $20 \mathrm{mg}$ dose, which was taken by only five volunteers. In this second investigation, ANG II was used as the agonist. Angiotensin II (Senn Chemicals, Dielsdorf, Switzerland) was dissolved in $0.9 \%$ $\mathrm{NaCl}$ to achieve a concentration of $1 \mu \mathrm{g} / \mathrm{mL}$. The doseresponse curve to establish the test dose of ANG II was carried out during the week preceding the first administration of DuP 753 using the same procedure described above. During study days 1 to 9 , the subjects came every day at $8 \mathrm{AM}$ and $8 \mathrm{PM}$ to the research facility for measurement of heart rate, weight, and blood pressure by a sphygmomanometer (sitting and standing). On study days 1 to 8 , the dose of DuP 753 or placebo was administered at $8 \mathrm{AM}$ in a similar fashion to the single-dose study. On days 1,4 , and 8, an ANG II challenge was performed before and again 6 and $12 \mathrm{~h}$ post-drug intake. Additional test doses were injected $24 \mathrm{~h}$ post drug on day 1 as well as 24,30 , and $36 \mathrm{~h}$ after the last dosing on day 8 .

Aldosterone was determined by a direct radioimmunoassay. ${ }^{12}$ For the measurement of plasma renin activity
(PRA), generated ANG I was trapped and quantitated by high affinity antibodies. ${ }^{13,14}$ For the quantitation of immunoreactive ANG II, a new method using monoclonal antibodies against ANG II was used. ${ }^{15}$ Norepinephrine was measured by a radioenzymatic assay. ${ }^{16,17}$ Subjects remained in a supine position for $30 \mathrm{~min}$ prior to blood sampling.

The data are provided as mean \pm SEM unless otherwise indicated. They were evaluated with a one way ANOVA model. A $P<.05$ was considered significant. The correlation coefficients were calculated, when indicated, by the method of least squares.

\section{RESULTS}

DuP 753 had no effect on resting blood pressure or pulse rate, neither after single administration nor during the 8 day treatment. The compound was well tolerated and no clinically significant side effect was observed in either of the two studies. Also, blood counts, the results of routine laboratory tests and urine analysis, and electrocardiogram measurements were not modified by DuP 753.

The changes in systolic blood pressure induced by the test dose of ANG I were calculated as the difference between post- and prechallenge values for each volunteer at each dose and at each time. Compared to placebo, no clear effect was observed with the doses of 2.5 and $5 \mathrm{mg}$. Doses of 10, 20, and $40 \mathrm{mg}$ induced however a dose-dependent inhibition of the response to ANG I. Figure 1 shows the dose-related inhibition of the response to ANG I expressed in percent of the baseline response. The peak inhibitory effect was reached 7,5 , and $3 \mathrm{~h}$ after intake of the 10,20 , and $40 \mathrm{mg}$ doses of DuP 753, respectively.

Compared to placebo, the 8 day treatment with DuP 753 taken once a day resulted in a dose-dependent re-

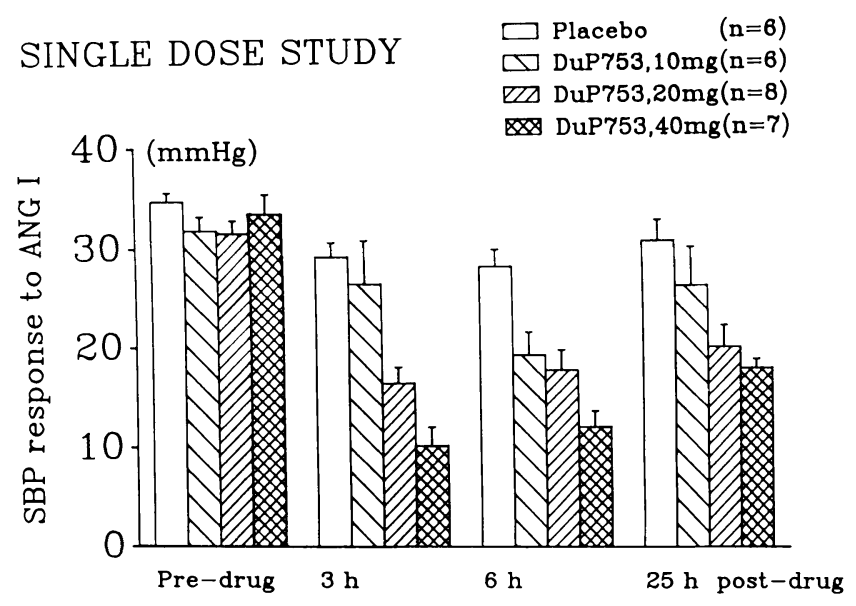

FIGURE 1. Effect of single doses of oral DuP $753(10,20$, or 40 $m g$ ) or placebo on the systolic blood pressure (SBP) response (mean $\pm S E M)$ to test doses of ANG I in healthy volunteers. Adapted from Christen et al. ${ }^{10}$ 
duction in the systolic blood pressure response to ANG II throughout the treatment period. The degree of blockade achieved with the 20 and $40 \mathrm{mg}$ doses was similar $6 \mathrm{~h}$ post-drug intake on days 1,4 , and $8(P<.01$ for effect of DuP $753 v$ placebo). On days 4 and 8 , however, the subjects receiving $40 \mathrm{mg}$ of DuP 753 showed a clear trend towards a reduced response to exogenous ANG II immediately before the morning dose of the drug (Figure 2).

Plasma aldosterone levels fell after administration of single doses of DuP 753, but a similar decrease was also seen after placebo. The single doses of DuP 753 produced a dose dependent increase in plasma ANG II, while no change was observed after placebo administration. As early as $30 \mathrm{~min}$ after the highest dose of $40 \mathrm{mg}$, a small rise was already apparent. No significant change in plasma norepinephrine was observed after single administration of DuP 753.

Figure 3 depicts the PRA and plasma ANG II levels measured at the beginning and at the end of repeated administration of placebo or DuP 753. Both PRA and ANG II showed a marked dose-dependent increase $6 \mathrm{~h}$ post-drug intake, and this rise was clearly more pronounced on day 8 than on day 1 . Both variables had already increased significantly $6 \mathrm{~h}$ after $20 \mathrm{mg}$ of DuP 753 on the first day, $(P<.05 v$ placebo). While the baseline results on day 1 were all very similar, on day 8 there was a trend for a dose-dependent increase even of the pre-drug values.

\section{DISCUSSION}

These data demonstrate that DuP 753 is a potent orally active ANG II antagonist with a relatively long duration of action. At peak effect, the $40 \mathrm{mg}$ dose induced an

\section{MULTIPLE DOSE STUDY}

$\square$ Placebo $(n=6)$ $\square$ DuP753,10mg(n=6) ED DuP753,20mg $(\mathrm{n}=5)$ DuP753,40mg $(n=6)$
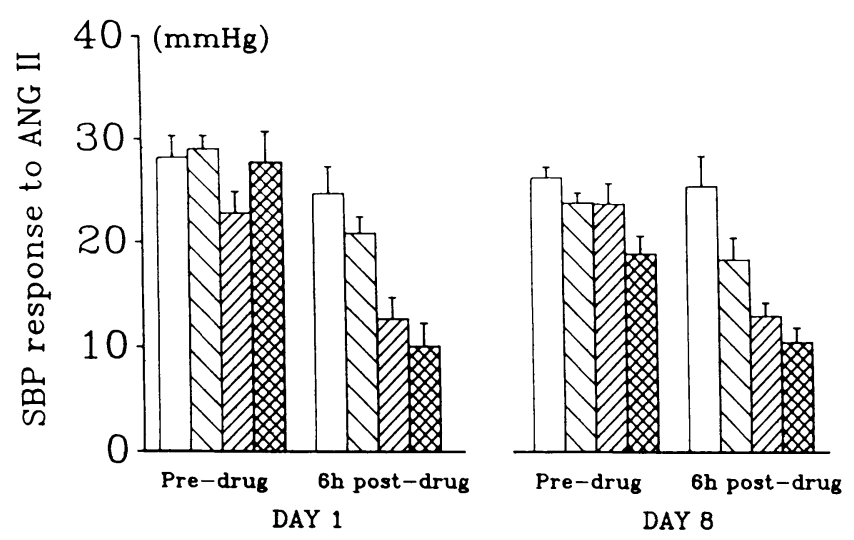

FIGURE 2. Effect of eight consecutive days of treatment with daily oral doses of DuP $753(10,20$, or $40 \mathrm{mg})$ or placebo on the systolic blood pressure $(S B P)$ response (mean \pm SEM) to test doses of ANG II in healthy volunteers. Adapted from Christen et al. ${ }^{10}$

\section{MULTIPLE DOSE STUDY}
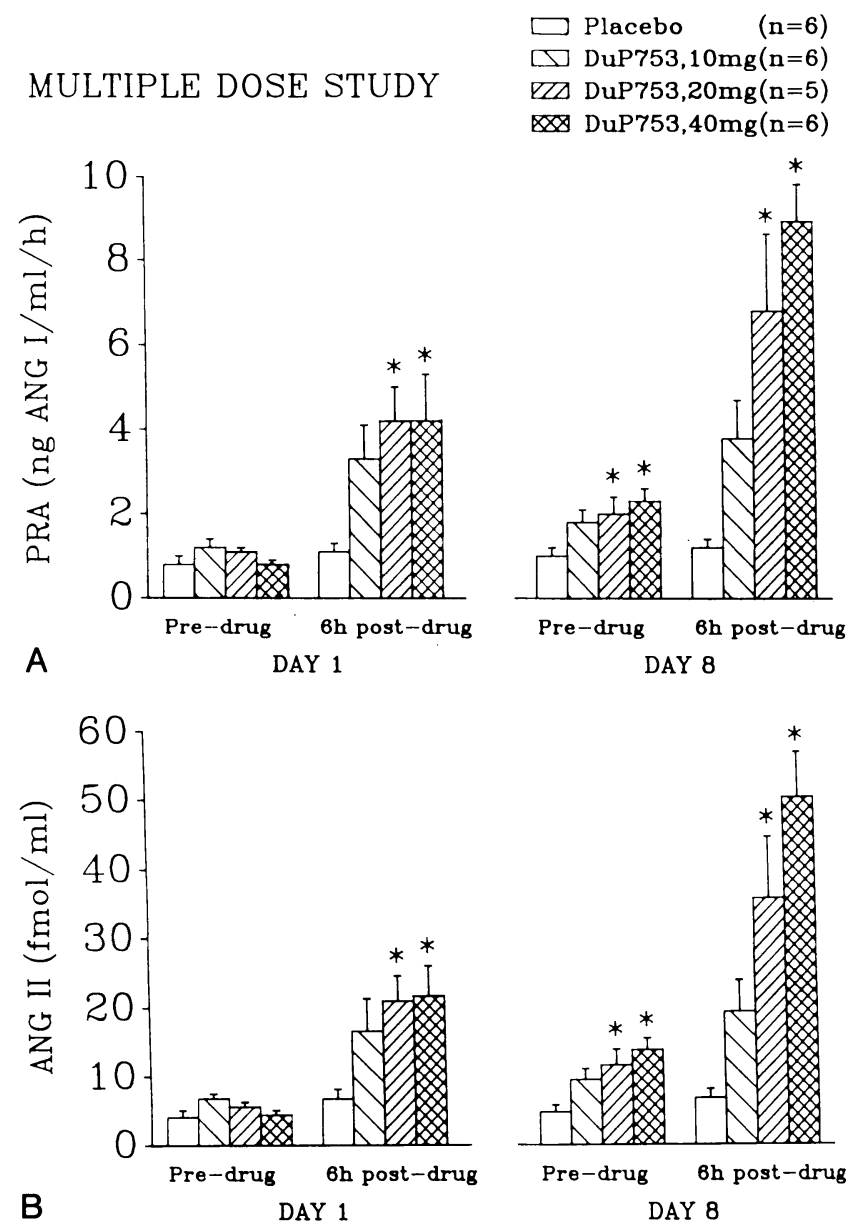

FIGURE 3. Effect of different doses of daily oral DuP 753 (10, 20 , or $40 \mathrm{mg})$ or placebo $(n=6$ for each dose except the dose of 20 $m g$ where $n=5$ ) on plasma renin activity and immunoreactive ANG II measured before and $6 \mathrm{~h}$ post-drug intake on days 1 and 8. Values are given as mean \pm SEM. ${ }^{*} \mathrm{P}<.05 \mathrm{v}$ placebo. Adapted from Christen et al. ${ }^{10}$

approximately $70 \%$ reduction in the systolic pressure response to ANG I or II. With this highest dose, even $24 \mathrm{~h}$ post-drug a definite effect was still present. Plasma renin activity and ANG II levels also responded with a dose-dependent compensatory rise as one might have expected based on earlier observations made with saralasin, ${ }^{2}$ as well as on the extensive experience accumulated with angiotensin converting enzyme (ACE) inhibitors. This compensatory rise was dose-dependent and more pronounced on day 8 of drug administration than on day 1 . This also is in agreement with findings obtained after administration of ACE inhibitors. ${ }^{18}$ The long duration of the blocking effect of DuP 753 is also reflected in the plasma renin activity and ANG II levels. Thus, while on day 1 all predrug measurements provided similar results, on day 8 , plasma renin activity as well as plasma ANG II were clearly increased before the administration of 20 and $40 \mathrm{mg}$ as compared to the pre-drug results obtained before placebo. 
No significant effect of the ANG II antagonist on plasma aldosterone could be detected. There are many possible reasons why there was no net effect of the drug on plasma aldosterone. Most importantly, the $40 \mathrm{mg}$ dose did not provide maximal receptor blockade at the vascular receptors. It is also conceivable that the repeated bolus injections of ANG I or II in the face of incomplete receptor blockade may have exerted a stimulating effect on aldosterone secretion.

The clinically most relevant question is of course how DuP 753 as a therapeutic agent compares to the various agents already available for blockade of the renin-angiotensin cascade. Obviously, the present study cannot provide any conclusive answer to this question since the drug was administered only to normal volunteers. Nevertheless, it is already evident that this ANG II antagonist exhibits features which appear particularly promising as a future therapeutic agent. Compared to saralasin it has the evident and decisive advantage of being orally active. Furthermore, while the present data cannot rule out the existence of an agonistic effect of DuP 753 because relatively small doses were administered, it seems likely that no such effect will occur in humans, since in various animal studies none was observed at very high doses of drug. ${ }^{7}$ These preliminary data obtained in normal volunteers do not allow us to predict the antihypertensive potency and efficacy of DuP 753. Nevertheless, the findings obtained with DuP 753 in hypertensive animals and the earlier observations made with saralasin suggest that DuP 753 will likely become an effective compound to treat hypertension and possibly congestive heart failure. Compared to angiotensin converting enzyme inhibitors, it would have the advantage of greater specificity. It shares with the ACE inhibitors, as well as with the renin inhibitors, the unescapable fact that the closed regulatory loop of renin secretion is fully operative, and as a consequence, blockade at any point beyond the renin secreting process automatically induces a compensatory rise in renin and ANG II. Whether this compensatory rise has any clinical consequences remains to be seen.

\section{REFERENCES}

1. Pals DT, Masucci FD, Sipos F, Denning CS, Jr.: A specific competitive antagonist of the vascular action of angiotensin II. Circ Res 1971;29:664-672.

2. Brunner HR, Gavras H, Laragh JH, Keenan R: Angiotensin II blockade in man by sar $^{1}$-ala ${ }^{8}$-angiotensin II for understanding and treatment of high blood pressure. Lancet 1973;ii:1045-1048.

3. Brunner HR, Gavras H, Laragh JH, Keenan R: Hypertension in man, exposure of the renin and sodium components using angiotensin II blockade. Circ Res 1974;34(suppl 1):35-43.
4. Streeten DHP, Anderson GH, Fruiberg JM, Dalakos TG: Use of an angiotensin II antagonist (saralasin) in the recognition of angiotensinogenic hypertension. N Engl J Med 1975;292:657-662.

5. Furukawa $Y$, Kishimoto $S$, Nishikawa $K$ : Hypotensive imidazole derivatives. US Patent $4,340,598$ issued to Takeda Chemical Industries, Ltd., Osaka, Japan, 1982.

6. Timmermans PBMWM, Carini DJ, Chiu AT, et al: Angiotensin II receptor antagonists. Am J Hypertens 1990;3:599-604.

7. Wong PC, Price WA, Chiu AT, et al: Nonpeptide angiotensin II receptor antagonists: VIII. Characterization of functional antagonism displayed by DuP 753, an orally active antihypertensive agent. J Pharmacol Exp Ther 1990;252:719-725.

8. Wong PC, Price WA, Chiu AT, et al: Hypotensive action of DuP 753, an angiotensin II antagonist in spontaneously hypertensive rats. Nonpeptide angiotensin II receptor antagonists: X. Hypertension 1990;15:459-468.

9. Wong PC, Price WA, Chiu AT, et al: Nonpeptide angiotensin II receptor antagonists: studies with EXP 9270 and DuP 753. Hypertension 1990;15:823-834.

10. Christen $Y$, Nussberger J, Waeber B, et al: Oral administration of DuP 753, a specific angiotensin II receptor antagonist, to normal volunteers; inhibition of the pressor response to exogenous angiotensin I and II. Circulation (in press).

11. Chiu AT, McCall DE, Price WA, et al: Nonpeptide angiotensin II receptor antagonists. VII. Cellular and biochemical pharmacology of DuP 753, an orally active antihypertensive agent. J Pharmacol Exp Ther 1990; 252:711-718.

12. Nussberger J, Waeber B, Brunner HR, et al: Highly sensitive microassay for aldosterone in unextracted plasma: comparison with two other methods. J Lab Clin Med 1984;104:789-796.

13. Poulsen $\mathrm{K}$, Jorgensen J: An easy radioimmunological microassay of renin activity, concentration and substrate in human and animal plasma and tissues based on angiotensin I trapping by antibody. J Clin Endocrinol Metab 1974;39:816-825.

14. Nussberger J, Fasanella d'Amore T, Porchet M, et al: Repeated administration of the converting enzyme inhibitor cilazapril to normal volunteers. J Cardiovasc Pharmacol 1987;9:39-44.

15. Nussberger J, Keller I, Waeber B, Brunner HR: Angiotensin II measurement with high-affinity monoclonal antibodies. J Hypertens 1988;6(suppl 4):S424-S425.

16. Peuler JD, Johnson GA: Simultaneous simple isotope radioenzymatic assay of plasma norepinephrine, epinephrine and dopamine. Life Sci 1977;21:625-636.

17. Laurent $S$, Juillerat L, London GM, et al: Increased response of brachial artery diameter to norepinephrine in hypertensive patients. Am J Physiol 1988;255:H36H43.

18. Mooser V, Nussberger J, Juillerat L, et al: Reactive hyperreninemia is a major determinant of plasma angiotensin II during ACE inhibition. J Cardiovasc Pharmacol 1990;35:276-282. 
